\title{
Short and Tall Stature
}

\author{
Jurgen H. Bramswig \\ University Children's Hospital, Münster, Germany
}

\section{Key Words}

Tall stature $\cdot$ Short stature $\cdot$ Height disorders •

Growth disorders $\cdot$ Psychosocial problems

\begin{abstract}
Short or tall stature is primarily a normal variation of height. It is part of the continuum of the normal Gaussian distribution curve which defines the lower and upper limit of normal as the $3 \mathrm{rd}$ and 97 th percentile. Within this context it is very important to differentiate normal variations in height and growth from pathological conditions. Normal variations in height are familial and idiopathic short or tall stature. Normal variations in growth are diagnosed as constitutional acceleration or constitutional delay of growth and puberty and are observed on all percentiles. Patients with pathological conditions of height usually have a syndromal, skeletal or chromosomal disorders such as Russell-Silver or Marfan syndrome, achondroplasia, Ullrich-Turner or Klinefelter syndrome. Many of the disorders with short stature have intrauterine growth retardation. The (mean) final height does not necessarily follow the target height range, but reaches a height below or above the population 3rd or 97th percentile. Patients with pathological conditions of growth can have short, normal or tall stature. They have a reduced or increased growth rate caused by a wide variety of chronic organic or psychosomatic diseases. At present, treatment with growth hormone $(\mathrm{GH})$ is available for patients with $\mathrm{GH}$ deficiency, Ullrich-Turner syndrome, chronic renal insufficiency, small for gestational age and Prader-Willi syndrome. The indication for $\mathrm{GH}$ treatment of idiopathic short stature is so far only approved in the USA. Adult height data indicate that patients with documented GH deficiency reach an adult
\end{abstract}

height within their target height range. For all other indications a statistically significant improvement in adult height has been documented. In the long-term follow-up of these patients not only a statistically significant but also a clinically relevant improvement in adult height should be demonstrated. Depending on the results, some of the indications for $\mathrm{GH}$ therapy might have to be reconsidered.

Copyright $\odot 2008$ Nestec Ltd., Vevey/S. Karger AG, Basel

\section{Introduction}

Normal height data are needed to define 'short' and 'tall' stature. Height data are specific for a certain population and vary widely, especially with ethnic background. They are collected within a defined population from cross-sectional, mixed cross-sectional and longitudinal height measurements or, rarely, from prospective longitudinal studies [1-5].

Short or tall stature means a length (birth to 2 years) or height (3-18 years) below or above the $3 \mathrm{rd}$ or 97 th percentile. This corresponds to -1.8 or +1.8 standard deviations (SDs) of the mean height for chronological age. Alternatively, heights below or above 2 SD (2.3rd or 97.7th percentile) are used to define short or tall stature. This definition implies that a certain percentage of the population will always be short or will always be tall. It does not mean that short or tall stature is necessarily the result of disease.

Normal stature is the result of a complex growth process. Pregnancy, genetic and ethnic influences, nutrition, endocrine function, general health as well as psychosocial well being are involved in the normal process of

\section{KARGER \\ Fax +4161306 1234 \\ E-Mail karger@karger.ch}

www.karger.com
(C) 2008 Nestec Ltd., Vevey/S. Karger AG, Basel 0517-8606/07/0653-0117\$23.50/0

Accessible online at:

www.karger.com/ane
Prof. Dr. Jurgen H. Bramswig

Albert Schweitzerstrasse 33

D-48129 Münster (Germany)

Tel. +49 251834 7730, Fax +49 2518347735

E-Mail bramswi@uni-muenster.de 
Table 1. Adult height (mean/median) in boys and girls of various countries

\begin{tabular}{|c|c|c|c|c|c|c|c|c|c|}
\hline & & \multicolumn{4}{|c|}{ Adult height in boys, $\mathrm{cm}$} & \multicolumn{4}{|c|}{ Adult height in girls, $\mathrm{cm}$} \\
\hline & & mean/median & $\mathrm{SD}$ & $+2 \mathrm{SD}$ & $-2 \mathrm{SD}$ & mean/median & SD & $+2 \mathrm{SD}$ & $-2 \mathrm{SD}$ \\
\hline The Netherlands & 1985 & 182.0 & 6.70 & 195.4 & 175.3 & 168.3 & 6.20 & 180.7 & 162.1 \\
\hline Germany & 1992 & 179.9 & 6.40 & 192.7 & 173.5 & 167.0 & 5.10 & 177.2 & 161.9 \\
\hline Sweden & 1976 & 179.8 & 6.69 & 193.2 & 173.1 & 165.9 & 6.56 & 179.0 & 159.3 \\
\hline Belgium & 1986 & 176.0 & 6.60 & 189.2 & 169.4 & 163.3 & 5.71 & 174.7 & 157.6 \\
\hline USA & 1977 & 176.8 & 6.60 & 190.0 & 170.2 & 163.7 & 5.93 & 175.6 & 157.8 \\
\hline England & 1995 & 176.6 & 6.95 & 190.5 & 169.7 & 163.7 & 6.02 & 175.7 & 157.7 \\
\hline France & 1979 & 174.5 & 6.00 & 186.5 & 168.5 & 163.2 & 5.60 & 174.4 & 157.6 \\
\hline Spain & 1988 & 175.6 & 6.04 & 187.7 & 169.6 & 161.3 & 5.72 & 172.7 & 155.6 \\
\hline Turkey & 1978 & 173.5 & 6.30 & 186.1 & 167.2 & 160.0 & 5.93 & 171.9 & 154.1 \\
\hline Mexico & 1975 & 172.8 & 7.19 & 187.2 & 169.5 & 160.6 & 7.39 & 175.4 & 153.2 \\
\hline Korea & 1979 & 170.2 & 5.22 & 180.6 & 165.0 & 157.6 & 4.76 & 167.1 & 152.8 \\
\hline Japan & 1990 & 170.4 & 5.60 & 181.6 & 164.8 & 157.9 & 5.00 & 167.9 & 152.9 \\
\hline
\end{tabular}

growth [6-8]. The result of this growth process is a height within the range of the $3 \mathrm{rd}$ and $97 \mathrm{th}$ percentile or a height just deviating from normal as in short or tall stature. It is important to remember that in most instances normal height, short and tall stature are the result of normal growth.

The ethnic variation in height is shown in table 1 for boys and girls. It demonstrates the large variability of height between populations. Normal adult height in the Netherlands is $168.3 \mathrm{~cm}$ for women and $182.0 \mathrm{~cm}$ for men $[9,10]$. This height compares to a mean normal height of 157.9 and $170.0 \mathrm{~cm}$ in Japanese women and men, respectively. The difference in the normal mean adult height between these two populations is $10.4 \mathrm{~cm}$ for women and $12.0 \mathrm{~cm}$ for men. The mean height in the Netherlands is equivalent to tall stature in Japan. Short stature in the Netherlands is just below the mean normal height in Japan.

The data in table 1 demonstrate the need to obtain population-specific growth charts to define short and tall stature. In a very height-conscious global society the variation in height is of national and international importance with respect to psychosocial adaptation. The answers to 'How tall is too tall' and 'How short is too short' depend on the height data obtained in each ethnic group. Extremes of height can be defined and accepted only when the normal variance in height of the reference population is known. For the majority of children, adolescents and adults a height below the 3rd or above the 97th percentile should be seen as part of a continuum of a normal Gaussian distribution curve. Only very few will have a defined abnormality, i.e. a height or growth disorder.

\section{Short Stature}

Short stature is defined as a height below the 3rd percentile. This means that $3 \%$ of the population have short stature. Short stature is defined as familial short stature when one or both parents have a height below the 3rd percentile. Children and adolescents with idiopathic short stature have parents with a height in the lower range of normal, but not below the 3 rd percentile. Their short stature probably represents the normal variation in height which can be observed in many families in which some children are taller or shorter than their siblings.

Familial and idiopathic short stature is best explained by estimating the target height according to Tanner [11]. Target height is the mean height of both parents adding $6.5 \mathrm{~cm}$ to obtain the target height for boys and subtracting $6.5 \mathrm{~cm}$ to define the target height for girls. The target height range is $\pm 8.5 \mathrm{~cm}$, corresponding to $2 \mathrm{SD}$. The adult height of $94 \%$ of the patients with familial or idiopathic short stature should fall into this target height range. The majority of patients with familial short stature will have a final height below the $3 \mathrm{rd}$ percentile due to the short stature of their parents. The majority of patients with idiopathic short stature will have a final height above the 3rd percentile due to the normal stature of their parents [12]. Puberty should not be delayed but start within the normal age ranges that are known for the different stages of puberty $[13,14]$.

Familial or idiopathic short stature is diagnosed from previous height measurements which demonstrate growth below, but parallel to the 3rd percentile. Height measurements of both parents should be obtained and 
documented on the child's growth chart together with the target height and the target height range. The physical examination and pubertal development should be normal and exclude pathological causes of short stature such as Russell-Silver syndrome, Ullrich-Turner syndrome, hypochondroplasia or other causes of syndromal, chromosomal or skeletal etiology $[11,15]$. It is essential that the normal growth curves of the population are available (table 1). For the majority of children, adolescents and adults, a height below the 3rd percentile should be seen as a normal variation in height. Very few children will have a defined clinical abnormality.

One of the major differential diagnoses in so-called familial or idiopathic short stature is the variation in growth, i.e. constitutional delay of growth and puberty (CDGP). It is also part of a continuum of the normal Gaussian distribution curve with respect to the age at onset of puberty and the time of the pubertal growth spurt. Statistically, it also occurs with a frequency of 3\%. A history of late pubertal development might be obtained from one or both parents or from older siblings. The diagnosis of CDGP is a preliminary diagnosis as long as puberty has not started. The already mentioned history of late puberty in the family and a retarded bone age of -2 or more years can point to the diagnosis. The final diagnosis of CDGP can only be made when the spontaneous onset of puberty occurs outside the $+2 \mathrm{SD}$ range of the reference population, i.e. 13.3 years for breast development Tanner stage B2 in girls and 13.6 years for spontaneous testicular growth of $>3 \mathrm{ml}$ in boys, referring to the data of the Zürich Longitudinal Growth Study [13, 14]. Growth delay and late pubertal development are the major reasons for referral of short patients. The Tanner growth curves for late onset of puberty as well as the data of Buckler and Wild [16] and Rikken and Wit [17] clearly demonstrate that boys and girls with CDGP will not follow their previous height or growth percentiles due to the late onset of their pubertal growth spurt. The already short adolescent will become even 'shorter' at a time when girls and boys with a normal onset of puberty have their pubertal growth spurt. A deviation from the growth curve is normal in these patients. It is necessary to explain this normal phenomenon of transient short stature combined with a late pubertal growth spurt in detail to the patient and his/her parents. The adult height will be within the target height range [12]. It is not necessary and usually confusing for the patients and parents, when an extensive workup is performed to confirm or exclude growth hormone $(\mathrm{GH})$ deficiency (GHD) as the cause of this normal variation of growth. A large number of these patients have been test- ed as 'transient GHD' [18-20]. Their correct diagnosis is most likely CDGP. It should be emphasized that CDGP is most often diagnosed in a patient with short stature but is also observed in adolescents with normal or tall stature and occurs, as already stated, with a frequency of $3 \%$.

It is one of the major challenges in pediatric endocrinology to differentiate normal variation in height, i.e. familial or idiopathic short stature, and normal variation in growth, i.e. CDGP from pathological causes of short stature and growth. Thus the pathology of short stature includes height and growth disorders.

Patients with short stature caused by height disorders have a short stature that follows a defined, disease-specific growth pattern. A typical example is the girl with Ullrich-Turner syndrome [21]. Her growth is clearly abnormal with respect to normal growth charts (fig. 1a), but exactly follows the specific and therefore normal growth pattern of Ullrich-Turner patients (fig. 1b). The same is true for many other diseases such as Down syndrome [2225], Noonan syndrome [26], achondroplasia [22, 27, 28] and other skeletal disorders [29]. Disease-specific growth charts have been created for these and other diseases through the tedious efforts of interested and engaged physicians. Thus patients with height disorders have a pathological short stature, but a normal, disease-specific growth pattern. With these disease-specific growth charts adult height can be projected when a patient finds and follows his/her individual growth channel. Deviation from the disease-specific growth curve indicates disease and needs evaluation, perhaps even treatment.

The growth pattern is different for patients with pathological short stature caused by growth disorders. The height of these patients initially follows the normal, population-based growth channel indicated by the height of the parents and the target height range. Figure 2 demonstrates the height and growth pattern of twins and the height and target height range of their parents. The twins have an almost identical height and growth pattern for the first 4 years. Then twin B deviates from the previous growth channel whereas twin A continues growing along the 50th percentile. Unfortunately, no workup of this pathological growth pattern was initiated so that the diagnosis of craniopharyngioma was delayed until the age of 8 years.

Abnormal growth can present a height in the normal range of the 3rd and 97th percentile or as short or tall stature. Thus, normal height does not exclude a pathological growth process. Growth is the major component of normality and pathology in short, normal or tall stature. 


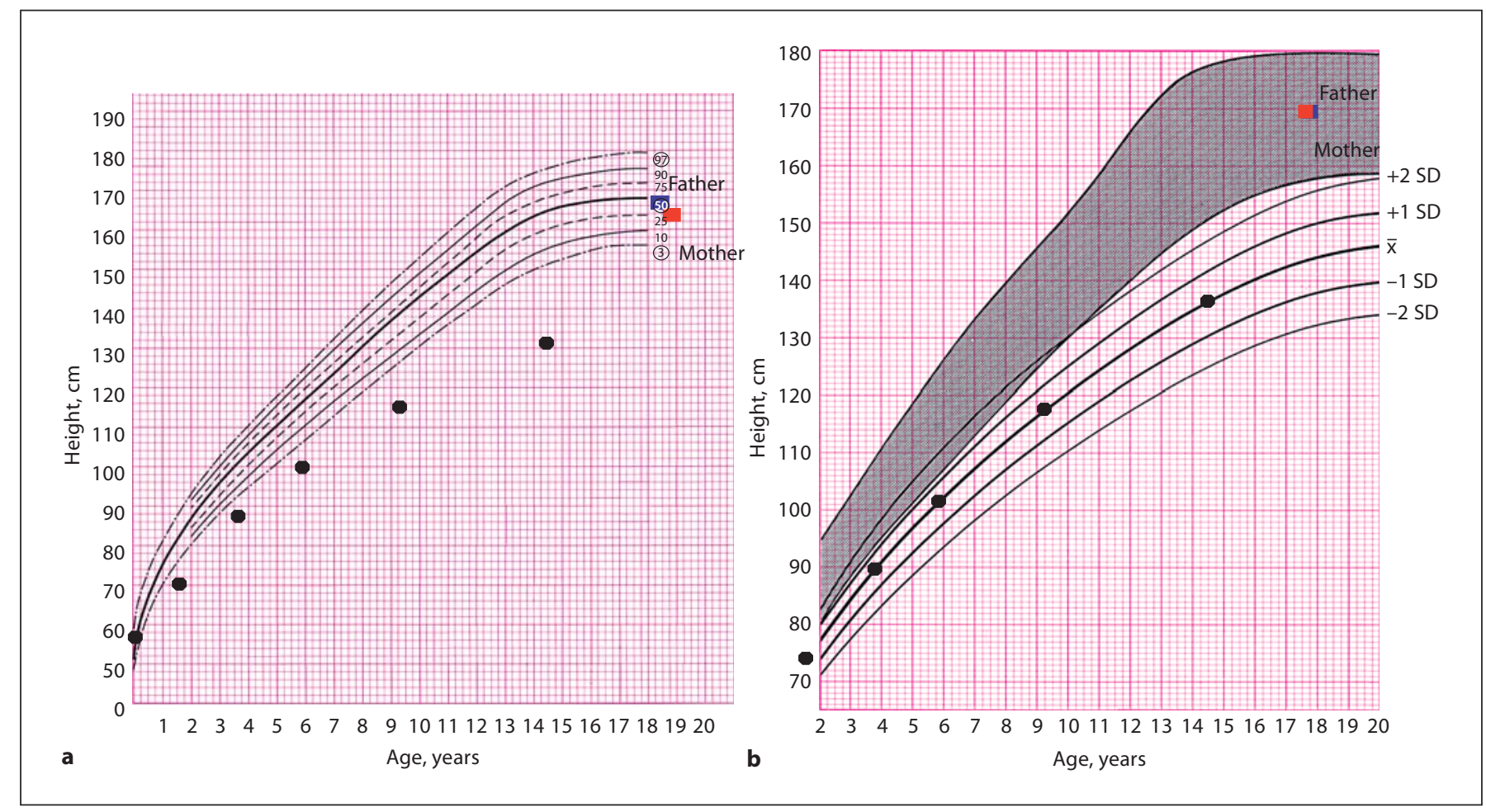

Fig. 1. a Growth curve $(\bullet)$ of a girl with Ullrich-Turner syndrome which deviates from the height percentiles of the reference population. $\mathbf{b}$ Normal growth of the same girl using Turner-specific growth charts.

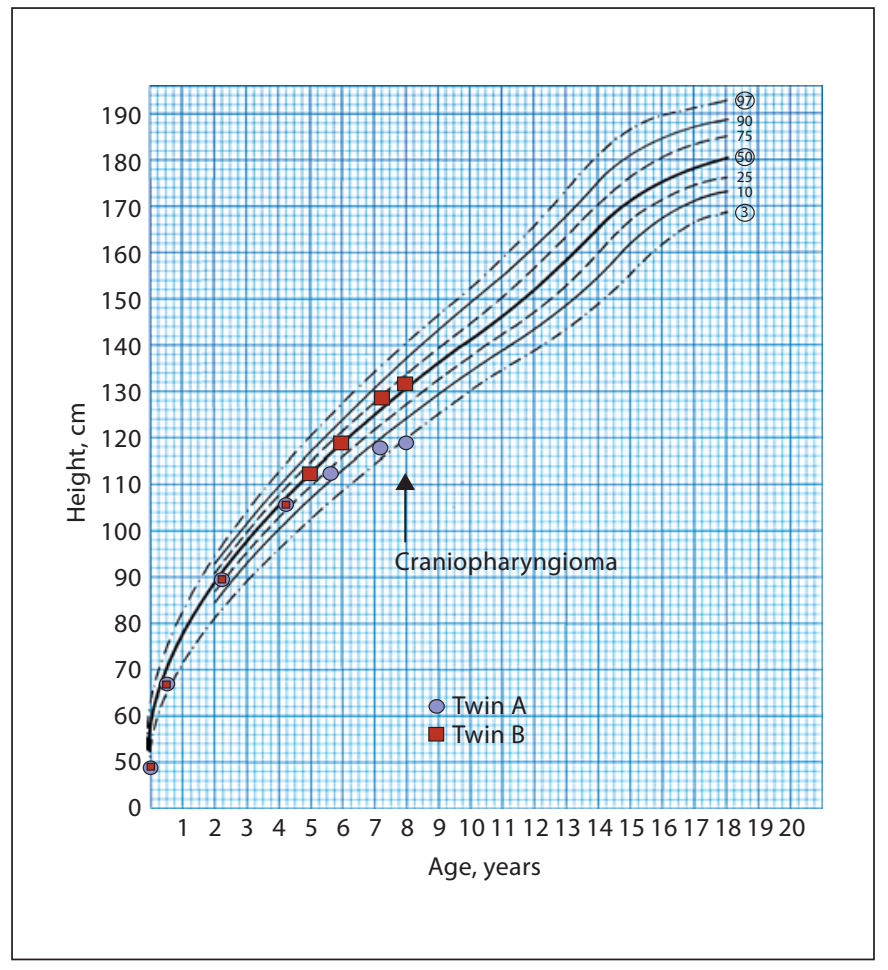

A large variety of mostly chronic diseases changes the previously maintained growth pattern. Height deviates from the normal growth channel when the specific disease becomes growth effective. Height can accelerate, as in patients with precocious puberty or congenital adrenal hyperplasia, or decelerate, as in hypothyroidism, GHD, craniopharyngioma or other mostly chronic diseases of various etiologies $[15,30,31]$.

One of the major causes of pathological growth with or without short stature is GHD. The incidence varies from 1:4,000 [32] to 1:10,000 [30]. Very few studies have looked into the incidence of GHD in the general population [32]. Most reports are from pediatric endocrine clinics which probably overestimate the true incidence of GHD.

Fig. 2. Growth curves of twin A and twin B demonstrating parallel growth until the age of 4 years. Twin B's growth deviates thereafter from the growth curve of his brother. A diagnosis of craniopharyngioma was made at the age of 8 years. 
Organic GHD has various causes. It includes tumors of the hypothalamic-pituitary area such as craniopharyngiomas or germinomas. It can also occur following pituitary surgery or cranial irradiation for brain tumors in localizations away from the hypothalamus and the pituitary as in medulloblastoma or in nasopharyngeal carcinoma. GHD becomes evident usually during childhood and adolescence, and in some cases much later, i.e. in adulthood, a long time after radiation therapy [33].

During the last several years our knowledge about the etiology of GHD in combination with other pituitary hormone deficiencies has greatly expanded. Several genetic defects of pituitary development and the GH-releasing hormone $(\mathrm{GHRH})-\mathrm{GH}$-insulin-like growth factor-1 (IGF-1) axis have been described [34, 35]. Most defects are associated with multiple pituitary hormone deficiencies, some affect GH secretion only. Low GH and IGF-1 levels lead to the diagnosis of GHD which could be called 'GHdependent growth failure'. The treatment of choice would be a substitution therapy with GH.

Before the initiation of GH therapy, an MRI of the hypothalamic-pituitary area should be obtained. The MRI should exclude tumors such as craniopharyngiomas and germinomas or demonstrate structural lesions such as an interrupted pituitary stalk, an ectopic neurohypophysis or a small or absent adenohypophysis. Detection of congenital abnormalities in the hypothalamic-pituitary area on MRI is important in explaining and confirming the diagnosis of GHD [36-38].

The long-term results of patients treated for GHD have greatly improved in recent years. The adult heights in proven GHD are usually close to target height or within the target height range $[39,40]$. One of the major improvements in handling the injections of $\mathrm{GH}$ was the introduction of daily subcutaneous GH injections instead of threeweekly intramuscular injections by Kastrup et al. [41].

In other cases the GH receptor and the IGF-1 system are affected $[34,35]$. GH levels are elevated with low IGF1 serum levels. This form of GHD would be an 'IGF-1dependent growth failure'. Other pituitary hormones are usually normal. The treatment of choice would be substitution therapy with IGF-1, an option that is not widely available so far.

In recent years the diagnosis of true GHD has become increasingly difficult. These difficulties have become evident when the diagnosis of GHD could not be confirmed during the long-term follow-up of pediatric patients with isolated GHD. GH stimulation tests were normal in a very high percentage of patients who were retested for GHD after the end of GH therapy $[42,43]$. It is so far un- explained why this change in GH secretion occurs. Transitory GHD [19] is one possible explanation, a wrong diagnosis the other reason. These patients are still prepubertal at a chronological age of 11-13 years when the diagnosis of GHD is made. They have very low, but 'normal' growth rates - very similar to patients with CDGP $[16,17]$. During this period GH secretion is obviously reduced in response to GH stimulation tests. The patients usually have isolated GHD, experience a late but normal pubertal growth spurt and reach an adult height within the target height range. When GH stimulation tests are repeated after the end of GH therapy normal results are frequently obtained. Thus, to avoid a 'wrong' diagnosis of GHD in this particular group of patients it might be necessary to lower the normal cutoff values for stimulated $\mathrm{GH}$ serum levels to $<10 \mathrm{ng} / \mathrm{ml}$ or perform estrogen or testosterone priming before the $\mathrm{GH}$ stimulation test.

The cutoff levels for GH following GH stimulation tests have changed since 1965 . When only a limited amount of pituitary GH was available, a maximum stimulated GH level of $<5 \mathrm{ng} / \mathrm{ml}$ was chosen. This somewhat arbitrary level was changed to $<7 \mathrm{ng} / \mathrm{ml}$ in 1975 and to $<10 \mathrm{ng} / \mathrm{ml}$ in 1985 [44]. There were no obvious reasons for this change and as prospective randomized controlled trials documented that $\mathrm{GH}$ levels between 5 and $10 \mathrm{ng} / \mathrm{ml}$ also indicated GHD.

Today, GH treatment is also possible for short patients who do not have GHD. GH therapy has been approved for girls with Ullrich-Turner syndrome since 1991, for patients with Prader-Willi syndrome since 2001, for children born small for gestational age since 2003, and for children with chronic renal insufficiency since 1995. GH secretion is generally normal, sometimes even increased as in chronic renal insufficiency, suggesting GH insensitivity as the possible cause of growth failure. In addition, the growth response to $\mathrm{GH}$ treatment is extremely variable and usually not comparable to the growth response seen in children with proven GHD.

The mean height gain over projected height in girls with Ullrich-Turner syndrome varies in different studies from 3.6 to $16.9 \mathrm{~cm}$ above projected height [45-47]. Height gains above $10 \mathrm{~cm}$ have been reported in studies that used considerably higher doses than the recommended therapeutic dose of $0.035 \mathrm{mg} / \mathrm{kg} / \mathrm{day}$. Some of the authors have stated that the higher doses are not justified for the small additional gain in height [45, 48-51].

The effects of GH in patients with Prader-Willi syndrome are not only height-, but also weight-related [50,51]. The initial reports have been promising, but long-term data are needed to evaluate the benefits of GH therapy. 
Children born small for gestational age can be treated with GH as approved by the Food and Drug Administration in 2001 and the European regulatory agency, EMEA, in 2003. A recent analysis of long-term GH therapy suggests an increase in adult height by 1 or more standard deviation scores (SDS) which is approximately $5-7 \mathrm{~cm}$ depending on the population standard $[52,53]$. Children with the greatest parental height-adjusted height deficit and children treated at a younger age have a better response to GH. Height gain is about 0.4 SDS, roughly 2.4 $\mathrm{cm}$ greater when a higher dose of $\mathrm{GH}$ is used. Here, the same question arises: can the additional costs and the possibly increasing side effects justify the higher dose of GH? The recommended dose in Europe is $0.035 \mathrm{mg} / \mathrm{kg} /$ day.

Children with chronic renal insufficiency have benefited from GH therapy in the initial treatment years. Limited data from long-term follow-up reports describe height gains of approximately 7-11 cm [54-56].

After these initial and some long-term data in patients with non-GHD short stature became available, it was not surprising that studies were initiated to document the growth response to $\mathrm{GH}$ in children with idiopathic short stature who were not GH deficient [57-60]. With the results of these studies and a reported gain in adult height of approximately $7 \mathrm{~cm}$, the Food and Drug Administration in the United States saw some evidence for the effectiveness of GH in the treatment of children with idiopathic short stature. Children with a height of more than 2.25 SDS (or less than the 1.2 percentile) below the mean for age and sex can be treated with GH after exclusion of other causes of short stature, and when they have a normal GH response on provocative testing, open epiphyses with a bone age within 2 SD of chronological age, and a growth rate showing that it is unlikely that the child will attain an adult height within the normal range. The lower limit of normal adult height is defined as $160.0 \mathrm{~cm}$ in men and $149.9 \mathrm{~cm}$ in women. It is not stated what method should be used to reliably predict this adult height, especially in children with a history of CDGP.

Final height data for $\mathrm{GH}$ treatment of idiopathic short stature have been published [59, 61, 62]. The mean gain in height over predicted height or a control group varies between 3.7 [59] and 5.4 or $7.2 \mathrm{~cm}$ when $\mathrm{GH}$ was administered at a dose of 34 or $53 \mu \mathrm{g} / \mathrm{kg} /$ day $[58,61]$.

The psychosocial impact of short stature has been evaluated in several studies with controversial results [63-68]. Some authors describe social, school and behavioral problems and low self-esteem, especially in patients referred to medical centers for evaluation of short stature
[63-68]. Others state that there is no evidence for major psychosocial problems in the general group of children, adolescents or adults with short stature [63-68]. The question whether we should offer GH therapy or psychosocial treatment for short stature is therefore open for further research. The effects of GH therapy on adult height, even if statistically significant, do not necessarily solve the psychosocial problems. It would therefore be appropriate to initiate and conduct prospective randomized controlled studies to examine the effects of medical versus psychosocial treatment on psychosocial functioning during GH treatment and during an observational follow-up period in adulthood. Foreseeing the difficulties of such a study, investigators should retrospectively evaluate the psychosocial functioning of $\mathrm{GH}$-treated patients. The results should be compared to a carefully selected control group of short adolescents and adults. It might be wise to delay large scale treatment of patients with nonGHD-deficient short stature, until the results of such a study are available.

\section{Tall Stature}

Tall stature is defined as a height above the 97th percentile. This means that $3 \%$ of the population have tall stature. Tall stature is called familial tall stature, when one or both parents have a height above the 97th percentile. Children and adolescents with idiopathic tall stature have parents with a height in the upper range of normal, but below the 97th percentile. Their tall stature probably represents the normal variation in height within a family or the positive secular trend in height.

The diagnosis of familial or idiopathic tall stature can generally be made from previous height measurements which demonstrate growth above but parallel to the 97th percentile, and a normal physical examination. For this diagnosis of a normal variant of height, reference growth curves of the population are needed (table 1).

The differential diagnosis includes overgrowth syndromes such as Sotos syndrome or sex chromosome disorders such as Klinefelter syndrome [69, 70]. Rarely is tall stature due to an excess of GH secretion caused by a pituitary adenoma or by an ectopic GHRH-producing tumor. Transient tall stature is observed in patients with true precocious and pseudo-precocious puberty. When untreated, these patients have a final height below their target height, sometimes even a height below the 3rd percentile.

Girls are more often referred for evaluation of familial or idiopathic tall stature than boys. Being already tall 
they would like to know how tall they will be as adults. Thus predictions of adult height play an important role in the management of tall stature. Whenever height predictions exceed a certain height, usually 3 SD above the population mean, treatment of tall stature might be considered by patients, parents and physicians.

Several height prediction methods are available. They are generally based on the assessment of bone age and some height-related variables. For the evaluation of bone age the Greulich-Pyle Atlas [71] and the Tanner-Whitehouse method of bone age determination [72] are most commonly used. The height prediction tables of Bayley and Pinneau [73] and Roche and Wettenhall [74] refer to the Greulich-Pyle Atlas, and the Tanner-Whitehouse Mark I or Mark II methods $[72,75]$ to the Tanner-Whitehouse method of bone age determination. Apart from bone age-related height predictions target height according to the method of Tanner [11] can be used. This is midparent height $+6.5 \mathrm{~cm}$ for boys and $-6.5 \mathrm{~cm}$ for girls with a range of $\pm 8.5 \mathrm{~cm}$.

Most height prediction methods are derived from height data on children growing within the $3 \mathrm{rd}$ and $97 \mathrm{th}$ percentile. No special attempt has been made to include children with tall or short stature. Therefore, when applied to untreated children with tall stature, the value of each prediction method has to be critically appraised. The accuracy of various prediction methods in untreated boys and girls with tall stature has been evaluated by different authors [70,76], the results of which have been summarized by Drop et al. [69]. There are major differences among the three methods. Some overestimate and others underestimate final height. For some methods there is no consistent tendency to over- or underestimate adult height. Whereas the Bayley-Pinneau method tends to overestimate adult height in all bone age groups in boys with tall stature, the Tanner-Whitehouse Mark I method overestimates adult height at younger and underestimates adult height at older bone ages, thus presenting the best result for the total group $[69,70]$. The Roche-WainerThissen method [74] underestimates adult height with the exception of 13-year-old boys. Generally and not surprising, height prediction methods become more accurate with increasing age. The largest error in height prediction occurs when the target height method is performed. Tall girls and tall boys exceed their target height on average by 9.36 or $13.37 \mathrm{~cm}$, respectively [70].

There are no established and generally accepted criteria for the treatment of an adolescent with tall stature. On the contrary, a long-lasting controversy has accompanied the treatment of tall stature [77]. Thus, treatment should be initiated only after the patient and her/his parents have been thoroughly informed about the accuracy of the height prediction method and the results and side effects of treatment.

A gender bias regarding treatment exists in the US. Treatment of tall stature is acceptable in girls, but rarely done in boys. In addition, treatment of tall stature is rarely performed in populations with a lower average height, though the phenomenon of tall stature is the same as well as the number of children with a height above the 97th percentile or above $3 \mathrm{SD}$.

The criteria for tall stature and thus the indication for treatment are different from author to author and have changed with time. The published predicted adult heights used as an indication for treatment vary between $175 \mathrm{~cm}$ in Swiss girls $[78,79]$ to $185 \mathrm{~cm}$ in German or Dutch girls $[69,70]$. In boys the reported heights are as low as $195 \mathrm{~cm}$ [80] and as high as $205 \mathrm{~cm}$. Most reports originate from Europe, Australia or the US.

High doses of estrogens or testosterone are generally used for the treatment of tall stature. The therapeutic regimen for boys varies only slightly in different publications. Testosterone enanthate is given at $500 \mathrm{mg}$ i.m. every 2 weeks. Treatment continues up to a bone age of 17 years, when $99 \%$ of the adult height is reached according to the Bayley-Pinneau prediction model. Ethinyl estradiol and conjugated estrogens are the basis of treatment in tall girls. Whereas the dose for conjugated estrogens remained the same with $0.625 \mathrm{mg} / \mathrm{day}$, the doses for ethinyl estradiol were reduced from 0.5 to $0.3 \mathrm{mg}$ and now to $0.1 \mathrm{mg} / \mathrm{day}[69,70]$. Estrogens are taken continuously without interruption. A gestagen is added, e.g. norethisterone acetate at a dose of $10 \mathrm{mg} /$ day or medroxyprogesterone acetate at a dose of $5 \mathrm{mg} / \mathrm{day}$, from day 19 to 28 of each cycle followed by menstrual bleeding.

The effect of treatment, i.e. the difference between predicted height and adult height, varies with the age at onset and the duration of therapy, the height prediction method used and the age when final height is measured. A longer, 2- to 3-year follow-up after the end of therapy is generally recommended until 'true' final height can be measured.

The mean height reductions vary from 4.8 to $12.7 \mathrm{~cm}$ in boys and from 3.6 to $5.3 \mathrm{~cm}$ in girls $[69,70]$. Bone agespecific data demonstrate that the height reduction clearly depends on the bone age at the start of therapy. At a younger bone age height is markedly more reduced. It amounts to 21.3 or $16.6 \mathrm{~cm}$ in the youngest and to 2.8 or $2.9 \mathrm{~cm}$ in the oldest bone age groups in boys and girls, respectively [70]. Heights in most of these patients were 
measured at the end of therapy when the bone age in boys was 17 years and in girls 15 years. Some additional growth has to be expected which will probably increase adult height by $1-2 \mathrm{~cm}$ in girls and $2-3 \mathrm{~cm}$ in boys. The reduction in adult height at the end of therapy is approximately $50-70 \%$ of the difference between the height before treatment and the predicted adult height using the Bayley-Pinneau method of height prediction [70]. Since some additional growth has to be expected the reduction in adult height amounts to approximately $40-50 \%$ of the predicted height gain without therapy. This height reduction as a percentage of the predicted height gain is obviously independent of the bone age at which treatment is initiated. It can serve as a 'rule of thumb' for patients and parents to describe the extent of the height reduction which can be achieved through therapy. Large individual variations will persist as indicated.

Individual patients have discontinued therapy for various reasons before reaching the recommended bone age of 17 years in boys. In a long-term follow-up we were able to demonstrate that the reduction in adult height was similar in these patients when compared to those treated until a bone age of 17 years. For this reason we initiated a short-term 6-month study in tall boys with a long-term follow-up and compared the results with the historical long-term therapy group [81]. Boys usually received highdose testosterone treatment for an average of 14 months. We compared treatment outcome in this group with the results in the 6-month study group. Height reduction was similar between the 2 groups with 7.5 and $7.555 \mathrm{~cm}$ in each group respectively. It is important to know that these results were not confirmed by another group with a smaller number of patients [82].

Short-term and some long-term side effects of treatment have been reported for boys and girls. Whereas acute side effects are sufficiently known, less is known about long-term side effects in women and men 30-40 years after therapy. High doses of estrogens and testosterone suppress the hypothalamic-pituitary-gonadal axis, well known from women using anti-conceptive therapy. Recovery of the hypothalamic-pituitary-gonadal axis was demonstrated by several investigators [83]. Spontaneous menstrual periods occurred from 3 to 6 months after the end of therapy in most patients. In men, sperm concentration and other ejaculate parameters were in the normal range or only slightly subnormal when compared to a control group with untreated tall stature [84] or a randomly selected group of men with normal stature [85].

Pregnancy and paternity are the 'final' proof of complete recovery of the suppressed hypothalamic-pituitary- gonadal axis. This has been documented, but less often. In a recent report from Australia $[86,87]$ the pregnancy rates between 371 treated and 409 untreated women were 77.4 and $76.5 \%$, and the rate of live births was 66.9 and $65.3 \%$, respectively. Additional data were obtained from study participants demonstrating that treated women were more likely to have tried for 12 or more months to become pregnant without success, that they were more likely to have seen a doctor because they were having difficulty becoming pregnant, and were more likely to have taken fertility drugs. The results of this report and the limited number of other reports make it necessary to add further information from previously treated women and men. The changing pattern of partnerships, marriages and child bearing has to be kept in mind when interpreting the forthcoming results.

Some patients experience different side effects during therapy. Most of these are mild and are reported only by a small number of patients. Acne in men and considerable weight gain in women are among the most frequently documented side effects. At the beginning of therapy peripheral edema can develop in girls and boys. They usually disappear when therapy is interrupted and restarted after a few weeks with the same or an initially lower dose that is increased to the recommended dose after a few weeks.

The weight gain in girls amounts to $5-10 \mathrm{~kg}$ or even more during the first 6 months of therapy. This is a problem especially for those patients who already have a tendency to be overweight before therapy. It should be known that the weight gain is considerably less during the following months of therapy. The total weight gain probably does not exceed the normal weight gain during puberty, but is concentrated at the beginning of therapy.

Psychosocial aspects of tall stature lead patients and parents to get information and treatment for their children. The impact of tall stature on girls or boys is fairly well documented for those patients who seek information or treatment for tall stature [88]. Very few data exist in an unselected patient group, a similar situation for patients with short stature. Fortunately, the acceptance of this treatment is high even several years after therapy. Among 91 men and 202 women, 91.2 and $89.6 \%$ accepted their treatment when they were $21.2 \pm 2.2$ and $20.2 \pm 2.3$ years old, respectively. Treated women and men had a height of $180.6 \pm 4.1$ or $197.5 \pm 4.4 \mathrm{~cm}$. When asked what height they would like to have the answer was 175.3 $\pm 3.8 \mathrm{~cm}$ in girls and $190.5 \pm 5.9 \mathrm{~cm}$ in boys which corresponds to approximately the 75 th percentile indicating that the actual height for most treated patients is still somewhat too tall. 


\section{Conclusion}

Treatment of tall stature is and will remain a controversial issue. The indication for treatment, the accuracy of height predictions, the effects of therapy with respect to a reduction in adult height or long-term side effects are only some of the many issues of debate. Ethical problems related to tampering with normal growth and excessive height can be added to the list of controversies. Some of the problems such as gonadal function and fertility could be solved by obtaining long-term follow-up data in later adulthood; others probably need prospective random- ized controlled studies when the question of height reduction between treated and untreated patients requires a definite answer.

The tall adolescent and her/his parents therefore need full information before therapy is initiated. Written informed consent should be obtained from the patient and her/his parents. Treatment of tall stature is performed for psychosocial and only rarely for medical reasons. Therefore, patients and parents should know that treatment of tall stature can be discontinued at all times when patients no longer want treatment or experience untoward side effects.

\section{References}

1 Tanner JM, Whitehouse RH: Clinical longitudinal standards for height, weight, height velocity, weight velocity, and stages of puberty. Arch Dis Child 1976;51:170-179.

2 Hesse V, Jaeger U, Kromeyer K, et al: What body height do our children have today? (The body height and body weight of 0 - to 16-year-old children, the Jena studies) (in German). Pädiatr Grenzgeb 1990;29:125127.

3 Ogden CL, Kuczmarski RJ, Flegal KM, et al: Centers for Disease Control and Prevention 2000 growth charts for the United States: improvements to the 1977 National Center for Health Statistics version. Pediatrics 2002; 109:45-60.

4 Reinken L, van Oost G: Longitudinal physical development of healthy children 0 to 18 years of age. Body length/height, body weight and growth velocity (in German). Klin Pädiatr 1992;204:129-133.

5 Prader A, Largo RH, Molinari L, Issler C: Physical growth of Swiss children from birth to 20 years of age. First Zurich longitudinal study of growth and development. Helv Paediatr Acta Suppl 1989;52:1-125.

6 Buckler JM: Growth at adolescence; in Kelnar CJ, Savage MO, Stirling HF, Saenger P (eds): Growth Disorders. Pathophysiology and Treatment. London, Chapman \& Hall, 1998, pp 179-194.

7 Stirling HF, Kelnar CJ: Growth in infancy and childhood; in Kelnar CJ, Savage MO, Stirling HF, Saenger P (eds): Growth Disorders. Pathophysiology and Treatment. London, Chapman \& Hall, 1998, pp 159-178.

8 Holmes R, Saenger P: Normal fetal growth; in Kelnar CJ, Savage MO, Stirling HF, Saenger P (eds): Growth Disorders. Pathophysiology and Treatment. London, Chapman \& Hall, 1998, pp 143-158.
9 Roede MJ: The secular trend in The Netherlands. The third nation-wide growth study. Arztl Jugendkd 1990;81:330-336.

10 Roede MJ, van Wieringen JC: Growth diagrams 1980. Netherlands third nation-wide survey. Tijdschr Soc Gezonheidsz 1985; 63(suppl):1-34.

11 Tanner JM: Growth at Adolescence, ed 2. Oxford, Blackwell, 1962.

12 Bramswig JH, Fasse M, Holthoff ML, et al: Adult height in boys and girls with untreated short stature and constitutional delay of growth and puberty: accuracy of five different methods of height prediction. J Pediatr 1990;117:886-891.

13 Largo RH, Prader A: Pubertal development in Swiss girls. Helv Paediatr Acta 1983;38: 229-243.

14 Largo RH, Prader A: Pubertal development in Swiss boys. Helv Paediatr Acta 1983;38 211-228.

15 Kelnar CJ, Savage MO, Stirling HF, Saenger P: Growth Disorders. Pathophysiology and Treatment. London, Chapman \& Hall, 1998.

16 Buckler JM, Wild J: Longitudinal study of height and weight at adolescence. Arch Dis Child 1987;62:1224-1232.

17 Rikken B, Wit JM: Prepubertal height velocity references over a wide age range. Arch Dis Child 1992;67:1277-1280.

18 Deal C: Is congenital growth hormone deficiency ever transient? Pediatr Endocrinol Rev 2005;2(suppl 3):355-362.

19 Gourmelen M, Pham-Huu-Trung MT, Girard F: Transient partial hGH deficiency in prepubertal children with delay of growth. Pediatr Res 1979;13:221-224.

20 Polychronakos C, Abu-Srair H, Guyda HJ: Transient growth deceleration in normal short children. A potential source of bias in growth studies. Eur J Pediatr 1988; 147:582583.
21 Ranke MB, Pfluger H, Rosendahl W, et al: Turner syndrome: spontaneous growth in 150 cases and review of the literature. Eur J Pediatr 1983;141:81-88.

22 Toledo C, Alembik Y, Aguirre Jaime A, Stoll C: Growth curves of children with Down syndrome. Ann Genet 1999;42:81-90.

23 Myrelid A, Gustafsson J, Ollars B, Anneren G: Growth charts for Down's syndrome from birth to 18 years of age. Arch Dis Child 2002; 87:97-103.

24 Arnell H, Gustafsson J, Ivarsson SA, Anneren G: Growth and pubertal development in Down syndrome. Acta Paediatr 1996;85: 1102-1106.

25 Cremers MJ, van der Tweel I, Boersma B, et al: Growth curves of Dutch children with Down's syndrome. J Intellect Disabil Res 1996;40:412-420.

26 Ranke MB, Heidemann P, Knupfer C, et al: Noonan syndrome: growth and clinical manifestations in 144 cases. Eur J Pediatr 1988;148:220-227.

27 Horton WA, Rotter JI, Rimoin DL, et al: Standard growth curves for achondroplasia. J Pediatr 1978;93:435-438.

28 Shurov VA, Kudrin BI, Diakin VM, Vlasova SS: Growth characteristics of children and adolescents with achondroplasia (in Russian). Pediatriia 1982;11:61-62.

29 Horton WA, Hall JG, Scott CI, et al: Growth curves for height for diastrophic dysplasia, spondyloepiphyseal dysplasia congenita, and pseudoachondroplasia. Am J Dis Child 1982;136:316-319.

30 Sizonenko PC, Clayton PE, Cohen P, et al: Diagnosis and management of growth hormone deficiency in childhood and adolescence. Part 1: diagnosis of growth hormone deficiency. Growth Horm IGF Res 2001;11: 137-165. 
31 Clayton PE, Cohen P, Tanaka T, et al: Diagnosis of growth hormone deficiency in childhood. On behalf of the Growth Hormone Research Society. Horm Res 2000;53(suppl 3):30.

-32 Lindsay R, Feldkamp M, Harris D, et al: Utah Growth Study: growth standards and the prevalence of growth hormone deficiency. J Pediatr 1994;125:29-35.

- 33 Murray RD, Darzy KH, Gleeson HK, Shalet SM: GH-deficient survivors of childhood cancer: GH replacement during adult life. J Clin Endocrinol Metab 2002;87:129-135.

-34 Lopez-Bermejo A, Buckway CK, Rosenfeld RG: Genetic defects of the growth hormoneinsulin-like growth factor axis. Trends Endocrinol Metab 2000;11:39-49.

- 35 Rosenfeld RG, Belgorosky A, CamachoHubner C, et al: Defects in growth hormone receptor signaling. Trends Endocrinol Metab 2007;18:134-141.

- 36 Arslanoglu I, Kutlu H, Isguven P, et al: Diagnostic value of pituitary MRI in differentiation of children with normal growth hormone secretion, isolated growth hormone deficiency and multiple pituitary hormone deficiency. J Pediatr Endocrinol Metab 2001; 14:517-523.

37 Maghnie M, Larizza D, Triulzi F, et al: Hypopituitarism and stalk agenesis: a congenital syndrome worsened by breech delivery? Horm Res 1991;35:104-108.

-38 Ochi M, Morikawa M, Yoshimoto M, et al: Growth retardation due to idiopathic growth hormone deficiencies: MR findings in 24 patients. Pediatr Radiol 1992;22:477-480.

- 39 Bramswig JH, Schlosser H, Kiese K: Final height in children with growth hormone deficiency. Horm Res 1995;43:126-128.

-40 Rikken B, Massa GG, Wit JM: Final height in a large cohort of Dutch patients with growth hormone deficiency treated with growth hormone. Dutch Growth Hormone Working Group. Horm Res 1995;43:135-137.

-41 Kastrup KW, Christiansen JS, Andersen JK, Orskov H: Increased growth rate following transfer to daily sc administration from three weekly im injections of hGH in growth hormone deficient children. Acta Endocrinol (Copenh) 1983;104:148-152.

42 Cacciari E, Tassoni P, Parisi G, et al: Pitfalls in diagnosing impaired growth hormone (GH) secretion: retesting after replacement therapy of 63 patients defined as GH deficient. J Clin Endocrinol Metab 1992;74: 1284-1289.

43 Clayton PE, Price DA, Shalet SM: Growth hormone state after completion of treatment with growth hormone. Arch Dis Child 1987; 62:222-226.

44 Hintz RL: The role of auxologic and growth factor measurements in the diagnosis of growth hormone deficiency. Pediatrics 1998; 102:524-526.
45 van Pareren YK, de Muinck Keizer-Schrama SM, Stijnen T, et al: Final height in girls with turner syndrome after long-term growth hormone treatment in three dosages and low dose estrogens. J Clin Endocrinol Metab 2003;88:1119-1125.

46 Ranke MB, Partsch CJ, Lindberg A, et al: Adult height after GH therapy in 188 UllrichTurner syndrome patients: results of the German IGLU Follow-up Study 2001. Eur J Endocrinol 2002;147:625-633.

47 Stahnke N, Keller E, Landy H: Favorable final height outcome in girls with UllrichTurner syndrome treated with low-dose growth hormone together with oxandrolone despite starting treatment after 10 years of age. J Pediatr Endocrinol Metab 2002;15: 129-138.

48 Carel JC, Mathivon L, Gendrel C, et al: Near normalization of final height with adapted doses of growth hormone in Turner's syndrome. J Clin Endocrinol Metab 1998;83: 1462-1466.

49 Carel JC: Growth hormone in Turner syndrome: twenty years after, what can we tell our patients? J Clin Endocrinol Metab 2005; 90:3793-3794.

50 Eiholzer U, l'Allemand D: Growth hormone normalises height, prediction of final height and hand length in children with PraderWilli syndrome after 4 years of therapy. Horm Res 2000;53:185-192.

51 Eiholzer U, Nordmann Y, l'Allemand D, et al: Improving body composition and physical activity in Prader-Willi Syndrome. J Pediatr 2003; 142:73-78

52 Van Pareren Y, Mulder P, Houdijk M, et al: Adult height after long-term, continuous growth hormone $(\mathrm{GH})$ treatment in short children born small for gestational age: results of a randomized, double-blind, doseresponse GH trial. J Clin Endocrinol Metab 2003;88:3584-3590

53 Dahlgren J, Wikland KA: Final height in short children born small for gestational age treated with growth hormone. Pediatr Res 2005;57:216-222.

54 Fine RN: Growth hormone treatment of children with chronic renal insufficiency, endstage renal disease and following renal transplantation-update 1997.JPediatrEndocrinol Metab 1997;10:361-370.

55 Fine RN, Sullivan EK, Tejani A: The impact of recombinant human growth hormone treatment on final adult height. Pediatr Nephrol 2000;14:679-681.

56 Haffner D, Schaefer F: Does recombinant growth hormone improve adult height in children with chronic renal failure? Semin Nephrol 2001;21:490-497.

57 Zadik Z, Zung A: Final height after growth hormone therapy in short children: correlation with siblings' height. Horm Res 1997;48: 274-277.
58 Wit JM, Boersma B, de Muinck KeizerSchrama SM, et al: Long-term results of growth hormone therapy in children with short stature, subnormal growth rate and normal growth hormone response to secretagogues. Dutch Growth Hormone Working Group. Clin Endocrinol (Oxf) 1995;42:365372.

59 Leschek EW, Rose SR, Yanovski JA, et al: Effect of growth hormone treatment on adult height in peripubertal children with idiopathic short stature: a randomized, doubleblind, placebo-controlled trial. J Clin Endocrinol Metab 2004;89:3140-3148.

60 Quigley CA: Growth hormone treatment of non-growth hormone-deficient growth disorders. Endocrinol Metab Clin North Am 2007:36:131-186

61 Wit JM, Rekers-Mombarg LT, Cutler GB, et al: Growth hormone $(\mathrm{GH})$ treatment to final height in children with idiopathic short stature: evidence for a dose effect. J Pediatr 2005; 146:45-53.

62 Crowe BJ, Rekers-Mombarg LT, Robling K, et al: Effect of growth hormone dose on bone maturation and puberty in children with idiopathic short stature. J Clin Endocrinol Metab 2006;91:169-175

63 Busschbach JJ, Rikken B, Grobbee DE, et al: Quality of life in short adults. Horm Res 1998;49:32-38.

64 Erling A: Why do some children of short stature develop psychologically well while others have problems? Eur J Endocrinol 2004;151(suppl 1):S35-S39.

- 65 Kranzler JH, Rosenbloom AL, Proctor B, et al: Is short stature a handicap? A comparison of the psychosocial functioning of referred and nonreferred children with normal short stature and children with normal stature. J Pediatr 2000;136:96-102.

66 Noeker M, Haverkamp F: Adjustment in conditions with short stature: a conceptual framework. J Pediatr Endocrinol Metab 2000;13:1585-1594.

67 Sandberg DE, Voss LD: The psychosocial consequences of short stature: a review of the evidence. Best Pract Res Clin Endocrinol Metab 2002;16:449-463.

68 Voss LD: Short normal stature and psychosocial disadvantage: a critical review of the evidence. J Pediatr Endocrinol Metab 2001; 14:701-711.

69 Drop SL, De Waal WJ, De Muinck KeizerSchrama SM: Sex steroid treatment of constitutionally tall stature. Endocr Rev 1998;19: 540-558.

70 Bramswig J: Diagnosis and treatment of tall stature. Monatsschrift Kinderheilkd 2004; 152:509-516.

71 Greulich WW, Pyle SI: Radiographic Atlas of Skeletal Development of the Hand and Wrist, ed 2. Stanford, Stanford University Press, 1959. 
72 Tanner JM, Landt KW, Cameron N, et al: Prediction of adult height from height and bone age in childhood. A new system of equations (TW Mark II) based on a sample including very tall and very short children. Arch Dis Child 1983;58:767-776.

$\checkmark 73$ Bayley N, Pinneau SR: Tables for predicting adult height from skeletal age: revised for use with the Greulich-Pyle hand standards. J Pediatr 1952;40:423-441.

74 Roche AF, Wettenhall HN: Stature prediction in short boys. Aust Paediatr J 1977;13: 261-264.

75 Tanner JM, Whitehouse RH, Marshall WA, Carter BS: Prediction of adult height from height, bone age, and occurrence of menarche, at ages 4 to 16 with allowance for midparent height. Arch Dis Child 1975;50:1426.

76 Joss EE, Temperli R, Mullis PE: Adult height in constitutionally tall stature: accuracy of five different height prediction methods. Arch Dis Child 1992;67:1357-1362.

-77 Bruinsma FJ, Venn AJ, Patton GC, et al: Concern about tall stature during adolescence and depression in later life. J Affect Disord 2006;91:145-152.
78 Zachmann M, Ferrandez A, Murset G, Prader A: Estrogen treatment of excessively tall girls. Helv Paediatr Acta 1975;30:11-30.

79 Zachmann M, Manella B, Eiholzer U, et al: Influence of oestrogen in high and low doses on plasma steroid concentrations in girls with tall stature and Turner syndrome. Acta Endocrinol (Copenh) 1984;106:368-373.

$>80$ Binder G, Grauer ML, Wehner AV, et al: Outcome in tall stature. Final height and psychological aspects in 220 patients with and without treatment. Eur J Pediatr 1997;156: 905-910.

81 Bramswig JH, von Lengerke HJ, Schmidt H, Schellong G: The results of short-term (6 months) high-dose testosterone treatment on bone age and adult height in boys of excessively tall stature. Eur J Pediatr 1988;148. 104-106.

82 Bettendorf M, Heinrich UE, Schonberg DK, Grulich-Henn J: Short-term, high-dose testosterone treatment fails to reduce adult height in boys with constitutional tall stature. Eur J Pediatr 1997;156:911-915.
83 Hanker JP, Schellong G, Schneider HP: The functional state of the hypothalamo-pituitary axis after high-dose oestrogen therapy in excessively tall girls. Acta Endocrinol (Copenh) 1979;91:19-29.

84 Lemcke B, Zentgraf J, Behre HM, et al: Longterm effects on testicular function of highdose testosterone treatment for excessively tall stature. J Clin Endocrinol Metab 1996; 81:296-301

$>85$ de Waal WJ, Torn M, de Muinck KeizerSchrama SM, et al: Long term sequelae of sex steroid treatment in the management of constitutionally tall stature. Arch Dis Child 1995;73:311-315.

$>86$ Pyett P, Rayner J, Venn A, et al: Using hormone treatment to reduce the adult height of tall girls: are women satisfied with the decision in later years? Soc Sci Med 2005;61: 1629-1639.

87 Venn A, Bruinsma F, Werther G, et al: Oestrogen treatment to reduce the adult height of tall girls: long-term effects on fertility. Lancet 2004;364:1513-1518.

>8 Sandberg DE, Bukowski WM, Fung CM, Noll RB: Height and social adjustment: are extremes a cause for concern and action? Pediatrics 2004;114:744-750. 